\title{
Influence of SCA on clinical outcomes and cervical alignment after laminoplasty in patients with multilevel cervical spondylotic myelopathy
}

Zheng Wang ${ }^{\dagger}$, Zhi-Wei Wang ${ }^{\dagger}$, Xi-Wen Fan, Zhen Liu, Jia-Yuan Sun, Wen-Yuan Ding and Da-Long Yang ${ }^{*}$ (D)

\begin{abstract}
Background: To study the impact of changes in spino-cranial angle (SCA) on sagittal alignment and to investigate the relationship between SCA and Neck Disability Index (NDI) scores after laminoplasty (LP)

Material and methods: In total, 72 patients with multilevel cervical spondylotic myelopathy (MCSM) after laminoplasty $(L P)$ were retrospectively enrolled. Based on the optimal cut-off values of preoperative SCA, patients were classified into low SCA and high SCA groups. Radiographic data were measured, including spino-cranial angle (SCA), T1-slope (T1S), C2-7 lordosis (CA), T1s minus CA (T1sCA), and C2-7 sagittal vertical axis (CSVA). JOA and NDI scores were both applied to assess postoperative and follow-up clinical efficacy. Pearson correlation coefficient and linear regression analysis were respectively calculated between radiographic data and between SCA and NDI.

Results: The preoperative SCA was significantly correlated with T1s $(r=-0.795)$, CA $(r=-0.857)$, and CSVA $(r=0.915)$. A receiver operating characteristic (ROC) curve model predicted a threshold of SCA (value of $85.2^{\circ}$ ). At the follow-up period, patients with lower SCA had a higher T1s and CA and a lower CSVA, simultaneously accompanied by greater $\triangle \mathrm{T} 1 \mathrm{~s}, \triangle \mathrm{CA}$, and $\triangle C S V A$. The linear regression model demonstrated that SCA in the higher group was positively correlated with NDI, and patients with higher SCA had worse NDI scores (pre: $p<0.001$; post: $p<0.001 ; \mathrm{F} / \mathrm{U}: p=0.003$ ) and greater changes of NDI (post: $p<0.010 ; \mathrm{F} / \mathrm{U}: p=0.002$ ).

Conclusion: SCA may be a good predictor of evaluating sagittal balance and planning surgery. Changes in sagittal alignment in the low SCA group were affected more easily, and a higher SCA was associated with worse quality of life. Laminoplasty could be a good choice for patients with lower SCA.
\end{abstract}

Keywords: Spino-cranial angle, Laminoplasty, Multilevel cervical spondylotic myelopathy, Neck Disability Index, Sagittal alignment

\footnotetext{
* Correspondence: yangdalong9999@163.com

†Zheng Wang and Zhi-Wei Wang contributed equally to this work. Department of Spinal Surgery, The Third Hospital of Hebei Medical University, 139 Ziqiang Road, Shijiazhuang 050051, People's Republic of China
}

(c) The Author(s). 2021 Open Access This article is licensed under a Creative Commons Attribution 4.0 International License, which permits use, sharing, adaptation, distribution and reproduction in any medium or format, as long as you give appropriate credit to the original author(s) and the source, provide a link to the Creative Commons licence, and indicate if changes were made. The images or other third party material in this article are included in the article's Creative Commons licence, unless indicated otherwise in a credit line to the material. If material is not included in the article's Creative Commons licence and your intended use is not permitted by statutory regulation or exceeds the permitted use, you will need to obtain permission directly from the copyright holder. To view a copy of this licence, visit http://creativecommons.org/licenses/by/4.0/ The Creative Commons Public Domain Dedication waiver (http://creativecommons.org/publicdomain/zero/1.0/) applies to the data made available in this article, unless otherwise stated in a credit line to the data. 


\section{Introduction}

Laminoplasty (LP), a commonly used indirect posterior decompression surgery for treating multilevel cervical spondylotic myelopathy (MCSM) degenerative diseases, is often related to clinical outcomes [1, 2]. It achieves sufficient decompression by drifting the spinal cord backwards [3]. Analysis of cervical alignment parameters is important to evaluate sagittal balance and to predict clinical outcomes. Recently, three pivotal sagittal parameters, spino-cranial angle (SCA), T1-slope (T1s), and C2-7 sagittal vertical axis (cSVA), were reported to be the focal point of future research [4]. Among them, SCA is a neglected but essential parameter, defined as the angle between a line from the sella turcica centre and C7 endplate and the C7 plateau line. Studies also reported that SCA is significantly correlated with many sagittal parameters [5]. Additionally, some cervical sagittal parameters are relevant to the health-related quality of life based on previously published literature $[6,7]$. However, whether SCA can be used as a predictor to affect the cervical alignment and clinical outcomes of patients with multilevel cervical spondylotic myelopathy (MCSM) following laminoplasty is unclear. Therefore, in the present study, we classified SCA into two categories based on the cut-off value to determine cervical sagittal balance and analyze the relationship between SCA and clinical outcomes after laminoplasty.

\section{Methods}

\section{Patient population}

A retrospective study of radiographic and clinical outcomes was performed in patients with multilevel cervical spondylotic myelopathy who received laminoplasty in the Department of Spinal Surgery, the Third Hospital of Hebei Medical University, from January 2011 to December 2016. The inclusion criteria were as follows: (1) three or more levels of compression were observed by MRI examination; (2) integrated radiographic and clinical data were collected; and (3) follow-up period of more than 24 months. The exclusion criteria were as follows: (1) previous cervical surgery; (2) cervical spine fracture, infection, and tumour; (3) ankylosing spondylitis and rheumatoid arthritis; (4) follow-up period less than 2 years; and (5) radiological parameters were too unclear to measure. Health-related outcomes, including Japanese Orthopaedic Association (JOA) (score 0-17) and Neck Disability Index (NDI) (range 0-50), were computed preoperatively, postoperatively, and at the follow-up period.

\section{Radiographic measurements}

Imaging results were calculated from standard lateral Xrays. All concerning sagittal parameters were evaluated (Fig. 1): (1) spino-cranial angle (SCA), the angle between

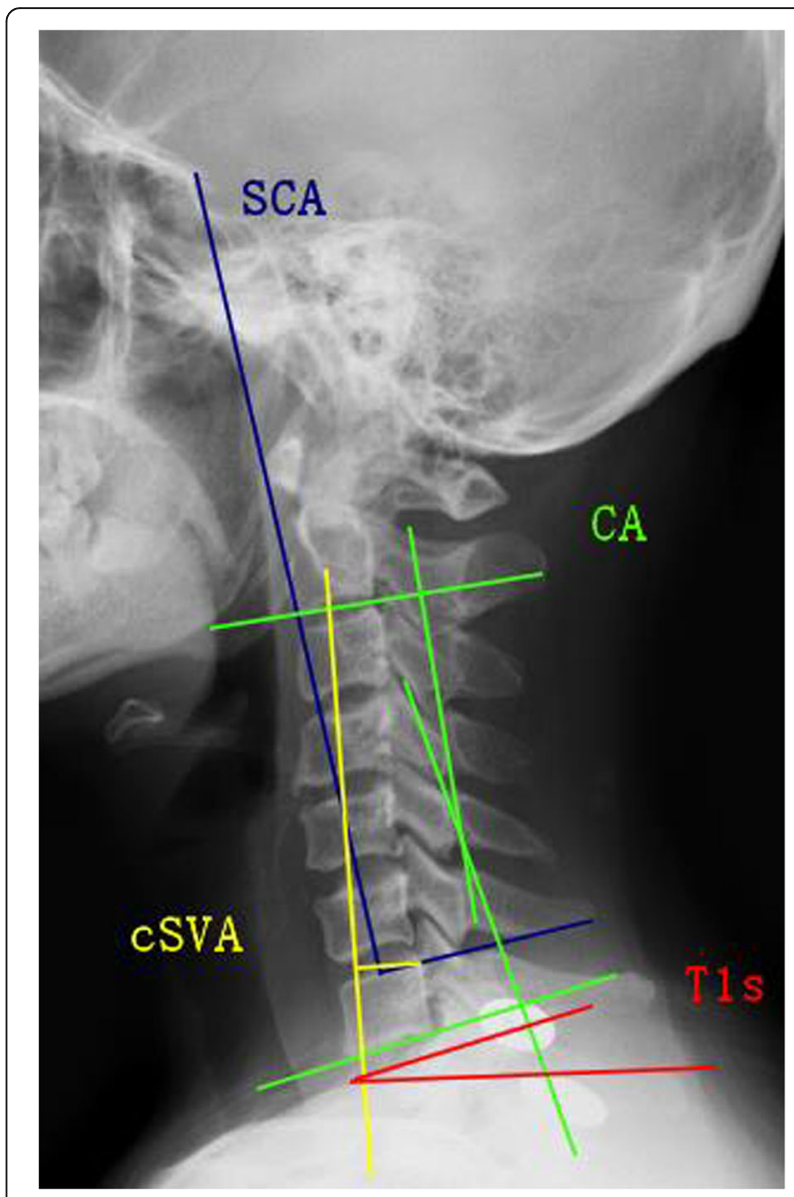

Fig. 1 Spino-cranial angle (SCA), the angle is defined between the C7 slope and the straight line joining the middle of the $\mathrm{C} 7$ end plate and the middle of the sella turcica. T1-slope (T1s), angle between a horizontal line and the superior endplate of $\mathrm{T1}$ or $\mathrm{C} 7$. C2-C7 lordosis (CA), angle between the lower plate of $\mathrm{C} 2$ and the lower plate of C7. C2-C7 SVA (CSVA), the distance from the posterior, superior corner of $\mathrm{C} 7$ to the plumbline from the centroid of $\mathrm{C} 2$

the $\mathrm{C} 7$ slope and the straight line joining the midpoint of the $\mathrm{C} 7$ endplate and the midpoint of the sella turcica; (2) T1-slope (T1s), the angle between a horizontal line and the upper endplate of $\mathrm{T} 1$; (3) $\mathrm{C} 2-7$ lordosis (CA), the angle defined from lower endplate of $\mathrm{C} 2$ to lower endplate of C7; (4) C2-7 sagittal vertical axis (cSVA), the distance between the $\mathrm{C} 2$ plumb line and the posterior upper endplate of C7; (5) T1s minus CA (T1sCA), the angle of T1-slope minus $\mathrm{C} 2-\mathrm{C} 7$ lordosis; (6) $\triangle$, the difference values between the preoperative and postoperative or preoperative and follow-up visit for each parameter, such as SCA, T1s, CA, cSVA, and T1sCA.

\section{Statistical analysis}

Receiver operating characteristic (ROC) curve was used to analyze the capacity of preoperative SCA to predict cervical sagittal alignment (Fig. 2), and patients were then divided into two categories based on the selected 


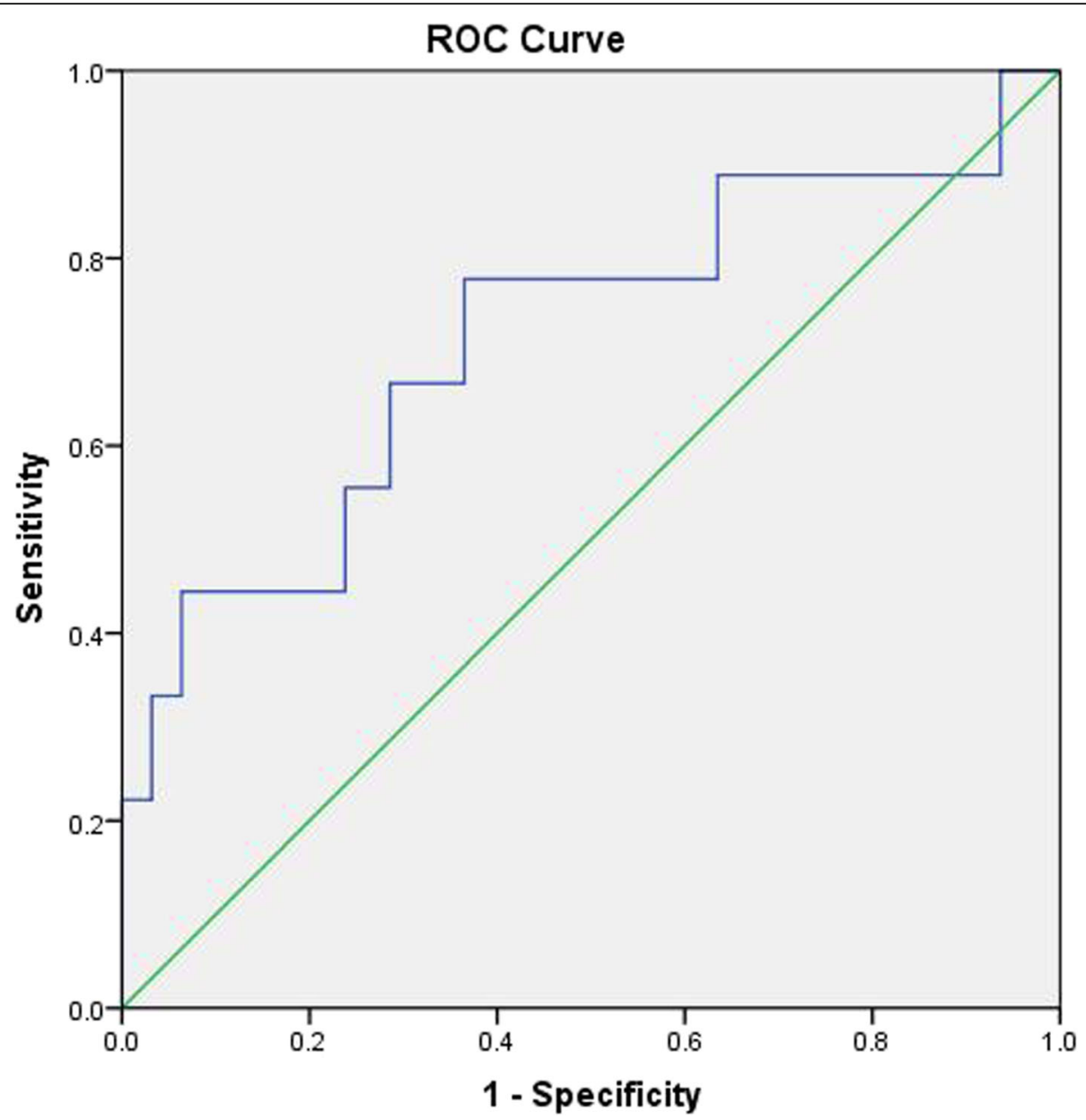

Fig. 2 ROC curves of cut-off values of SCA for predicting sagittal balance. AUC result for cut-off values of SCA was 0.716. AUC, area under the curve; ROC, receiver operating characteristics; SCA, spino-cranial angle

optimal cut-off value of preoperative SCA. All data were statistically calculated by the SPSS software (version 22.0; SPSS Inc., Chicago, IL, USA) and presented as the means \pm standard deviation. Pearson correlation coefficient was compared between SCA and other radiographic sagittal parameters. Linear regression analysis was applied to assess the relationships between SCA and NDI scores. Independent samples $t$ test or MannWhitney $U$ test was used to compare cervical sagittal alignment parameters and health-related outcomes between two groups. $P<0.05$ was considered statistically significant.

\section{Results}

\section{Analysis of ROC curve and cut-off value}

As a criterion for judging balance, T1sCA was applied to assess sagittal balance ( $\mathrm{T} 1 \mathrm{sCA} \leq 20^{\circ}$, cervical balance; > $20^{\circ}$, cervical imbalance). Analysis of the ROC curve for sagittal balance revealed that preoperative SCA of $85.2^{\circ}$ was considered the optimal cut-off value. The AUC and
$P$ value were 0.716 and 0.051 , respectively, for the cutoff value of SCA (Fig. 2).

\section{Comparison of patient characteristics based on preoperative SCA}

Seventy-two patients were identified in this study. Their demographic data are summarized in Table 1. All the surgeries were completed successfully (Fig. 3).The

Table 1 Patient characteristics

\begin{tabular}{llll}
\hline & LG $(\boldsymbol{n}=\mathbf{4 1})$ & HG $(\boldsymbol{n}=\mathbf{3 1})$ & $\boldsymbol{P}$ value \\
\hline No. of patients & 41 & 31 & \\
Age (year) & $59.34 \pm 7.95$ & $57.58 \pm 9.92$ & 0.406 \\
Sex (male/female) & $22 / 19$ & $15 / 16$ & 0.658 \\
Operation time (min) & $125.85 \pm 30.58$ & $121.61 \pm 27.58$ & 0.766 \\
Length of hospitalization & $7.54 \pm 1.50$ & $8.90 \pm 1.58$ & 0.002 \\
Operative segments & $3.29 \pm 0.60$ & $3.45 \pm 0.68$ & 0.229 \\
Blood loss & $182.68 \pm 57.58$ & $195.48 \pm 64.54$ & 0.459
\end{tabular}

LG low SCA group, HG high SCA group, SCA spino-cranial angle 


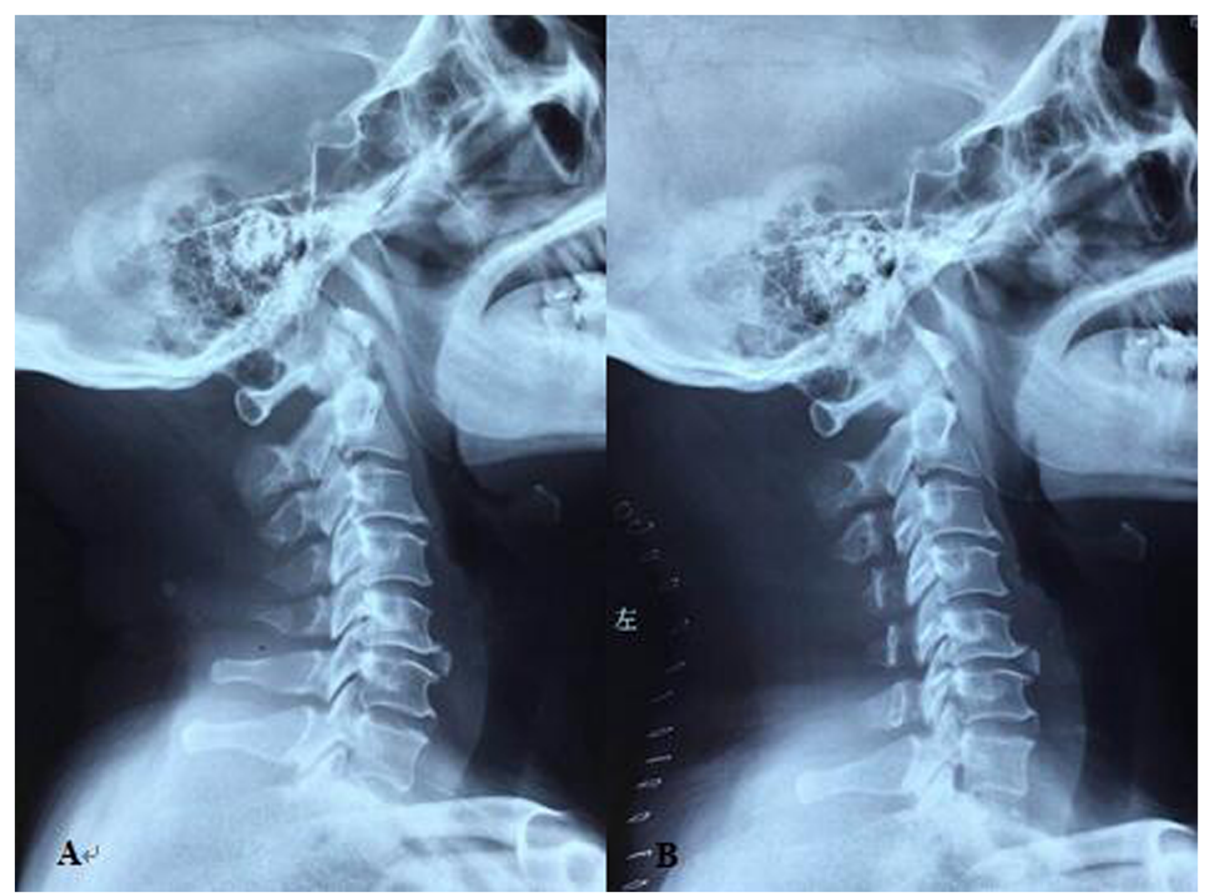

Fig. 3 Laminoplasty was performed to release the compression. Lateral X-ray of cervical spine was taken in a 50-year-old male patient with MCSM preoperatively $\mathbf{a}$ and at the 2-year follow-up visit $\mathbf{b}$, and sagittal parameters were corrected appropriately

average length of hospitalization $(\mathrm{LOH})$ was $7.54 \pm 1.50$ in the low SCA group and $8.90 \pm 1.58$ in the high SCA group, which was statistically significant $(P=0.002)$. Other variables, such as age, sex, operation time, operative segments, and blood loss, were not statistically significant between the two groups.

\section{Correlation between SCA and other sagittal parameters}

Significant correlations were found between SCA and T1-slope (T1s) $(r=-0.795, P<0.001)$, between SCA and C2-C7 lordosis (CA) $(r=-0.857, P<0.001)$, and between SCA and C2-C7 SVA (cSVA) $(r=0.915, P<$ 0.001 ). No correlation was shown between SCA and T1sCA $(r=0.072, P=0.546) . P$ values and correlations between the different parameters are shown in Table 2.

Table 2 Correlation between pre-SCA and other sagittal parameters

\begin{tabular}{llll}
\hline Parameters & Correlation & $\boldsymbol{P}$ value & Significance \\
\hline T1s $\left(^{\circ}\right)$ & -0.795 & $<0.001$ & $\mathrm{~S}$ \\
$\mathrm{CA}\left({ }^{\circ}\right)$ & -0.857 & $<0.001$ & $\mathrm{~S}$ \\
CSVA $(\mathrm{mm})$ & 0.915 & $<0.001$ & $\mathrm{~S}$ \\
T1sCA $\left(^{\circ}\right)$ & 0.072 & 0.546 & $\mathrm{NS}$ \\
\hline
\end{tabular}

SCA spino cranial angle, T1s T1-Slope, CA C2-7 lordosis angle, CSVA C2-7 sagittal vertical axis, $T 1 s C A$ T1s minus $C A$
Correlation between SCA and health-related quality of life (HRQOL) scores

According to linear regression model analysis, SCA was not significantly correlated with the JOA scores. However, for NDI, the results were rather interesting. Whether at the preoperative, postoperative, or follow-up period, SCA in the higher group was all positively correlated with the NDI scores (pre: $r=0.876, P<0.001$; post: $r=0.414, P=$ 0.020; F/U: $r=0.431, P=0.015$ ). However, in the lower SCA group, there was no significant correlation between SCA and NDI scores preoperatively $(r=0.159, P=0.320)$, postoperatively $(r=0.055, P=0.731)$, or at the follow-up period $(r=-0.005, P=0.947)$ (Table 3).

Table 3 Correlation between SCA and NDI scores in the two groups

\begin{tabular}{llll}
\hline & & LG & HG \\
\hline Pre & $r$ & 0.159 & 0.876 \\
& $P$ & 0.320 & $<0.001$ \\
Post & $r$ & 0.055 & 0.414 \\
& $P$ & 0.731 & 0.020 \\
F/U & $r$ & -0.005 & 0.431 \\
& $P$ & 0.974 & 0.015 \\
\hline
\end{tabular}

Pre preoperative, Post postoperative, F/U follow-up, LG low SCA group, HG high SCA group, SCA spino-cranial angle 


\section{Comparison of clinical outcomes based on preoperative SCA}

Both groups showed significant improvement in JOA and NDI scores after laminoplasty. Compared with patients with lower SCA, patients in the higher SCA group expressed higher NDI at various time points (pre 25.58 \pm 5.74 vs $19.80 \pm 4.77, P<0.001$; post $17.90 \pm 4.36$ vs $13.78 \pm 3.70, P<0.001 ; \mathrm{F} / \mathrm{U} 15.84 \pm 4.85$ vs $12.39 \pm 3.58$, $P=0.003)$. The changes of NDI in the high SCA group exceeded those in the low SCA group (pre vs post: $P=$ 0.010; pre vs $\mathrm{F} / \mathrm{U}: P=0.002$ ). However, JOA scores and $\triangle \mathrm{JOA}$ failed to reach significance between the two groups (Table 4). The changes in the above clinical results are shown in the form of a line chart (Fig. 4).

\section{Comparison of radiographic parameters based on preoperative SCA}

Tables 5 and 6 summarize the preoperative, postoperative, and follow-up values and changes of radiographic parameters. The mean \pm standard deviation values of pre-SCA, post-SCA, and F/U-SCA were $75.65^{\circ} \pm 5.08^{\circ}$, $81.59^{\circ} \pm 7.76^{\circ}$, and $82.88^{\circ} \pm 7.42^{\circ}$ in the low SCA group and $93.15^{\circ} \pm 5.25^{\circ}, 95.45^{\circ} \pm 6.09^{\circ}$, and $96.17^{\circ} \pm 5.26^{\circ}$ in the high SCA group, respectively, which all displayed significant differences $(P<0.001)$. Before laminoplasty, compared with patients in the low SCA group, patients with higher SCA had smaller T1s $(P<0.001)$ and CA $(P$ $<0.001)$ and larger cSVA $(P<0.001)$. The trends were maintained at the postoperative (T1s: $P<0.001$; CA: $P<$ 0.001; cSVA: $P<0.001$ ) and follow-up periods (T1s: $P<$ 0.001; CA: $P<0.001$; cSVA: $P<0.001)$. Unfortunately, preoperative T1sCA did not differ significantly between the two groups $(P=0.348)$, nor did the postoperative $(P$

Table 4 Quality of clinical parameters

\begin{tabular}{llll}
\hline & LG $(\boldsymbol{n}=\mathbf{4 1})$ & HG $(\boldsymbol{n}=\mathbf{3 1})$ & $\boldsymbol{P}$ value \\
\hline JOA & & & \\
Pre & $10.17 \pm 2.12$ & $9.84 \pm 2.18$ & 0.589 \\
Post & $12.59 \pm 1.34$ & $12.52 \pm 1.65$ & 0.931 \\
F/U 2 years & $13.46 \pm 0.81$ & $13.19 \pm 1.17$ & 0.208 \\
$\Delta$ JOA (pre vs post) & $2.41 \pm 1.58$ & $2.68 \pm 1.58$ & 0.475 \\
$\Delta$ JOA (pre vs F/U) & $3.29 \pm 2.15$ & $3.35 \pm 1.80$ & 0.949 \\
Pre vs F/U & $<0.001$ & $<0.001$ & \\
NDI & & & $<0.001$ \\
Pre & $19.80 \pm 4.77$ & $25.58 \pm 5.74$ & $<0.001$ \\
Post & $13.78 \pm 3.70$ & $17.90 \pm 4.36$ & 0.003 \\
F/U 2 years & $12.39 \pm 3.58$ & $15.84 \pm 4.85$ & 0.010 \\
$\Delta$ NDI (pre vs post) & $-6.02 \pm 2.29$ & $-7.68 \pm 2.98$ & 0.002 \\
$\Delta$ NDI (pre vs F/U) & $-7.41 \pm 2.93$ & $-9.74 \pm 3.63$ & \\
Pre vs F/U & $<0.001$ & $<0.001$ & \\
\hline
\end{tabular}

LG low SCA group, HG high SCA group, JOA Japanese Orthopaedic Association, NDI Neck Disability Index
$=0.213)$ or follow-up T1sCA $(P=0.661)$ (Table 5). Interestingly, patients with lower preoperative SCA following laminoplasty had significantly greater alignment changes than those in the higher group at the postoperative and follow-up periods, such as $\triangle$ SCA (pre vs post: $P$ $=0.019$; pre vs F/U: $P=0.005$ ), $\triangle$ T1s (pre vs post: $P=$ 0.007 ; pre vs $\mathrm{F} / \mathrm{U}: P=0.028$ ), and $\triangle \mathrm{CA}$ (pre vs post: $P=$ 0.005 ; pre vs $\mathrm{F} / \mathrm{U}: P=0.017)$. Concerning cSVA, although ${ }$ CSVA (pre vs post) did not show the same significant trend as mentioned above $(5.57 \mathrm{~mm} \pm 5.84 \mathrm{~mm}$ vs $2.52 \mathrm{~mm} \pm 6.89 \mathrm{~mm})(P=0.055)$, a significant difference was revealed between the two groups at the followup period $(7.51 \mathrm{~mm} \pm 8.03 \mathrm{~mm}$ vs $3.61 \mathrm{~mm} \pm 5.76 \mathrm{~mm})$ $(P=0.019)$. Unfortunately, a statistically significant difference in $\triangle \mathrm{T} 1 \mathrm{sCA}$ was not found between the two groups either after surgery or during the follow-up (Table 6). The changes in the above radiographic parameters are shown in the form of a line chart (Fig. 5).

\section{Discussion}

Multilevel cervical spondylotic myelopathy (MCSM) is a common disease, in which severe spinal cord compression is caused by the degeneration of multiple levels of intervertebral discs, joints, and ligaments and is often accompanied by severe clinical neurological deficits [811]. As a rather logical and popular surgical approach for the cure of MCSM, laminoplasty (LP) drifts the spinal cord backwards, resulting in indirect decompression $[3,12]$. However, it may cause sagittal imbalance, such as the loss of cervical lordosis and the generation of kyphosis, which is associated with poor neck function [6, 13-15].

In recent years, spino-cranial angle (SCA), T1-slope (T1s), and C2-7 sagittal vertical axis (cSVA) have been considered the three most important parameters of the sagittal alignment for future study [4]. In our study, we followed the new sagittal parameter SCA to assess the association of SCA with other cervical sagittal parameters and postoperative recovery index. Under normal conditions, the sagittal angle of SCA fluctuates within a certain range $\left(83^{\circ} \pm 9^{\circ}\right)$ and has been reported to be affected by certain sagittal parameters, such as T1-slope (T1s) and C2-7 lordosis (CA) [5], consistent with our findings (T1s: $r=-0.795, P<0.001$; CA: $r=-0.857, P$ $<0.001)$. The T1s and CA values were significantly correlated with the NDI, according to previous literature [16]. In this study, we found that SCA was correlated with T1s $(r=-0.795, P<0.001)$ and CA $(r=-0.857, P$ $<0.001)$ as well as directly correlated with the NDI scores in the high SCA group (pre: $r=0.876, P<0.001$; post: $r=0.414, P=0.020, \mathrm{~F} / \mathrm{U}: r=0.431, P=0.015)$, proving that SCA could significantly influence cervical alignment. Only when SCA exceeds a certain threshold does NDI increase as SCA increases. At the same time, 


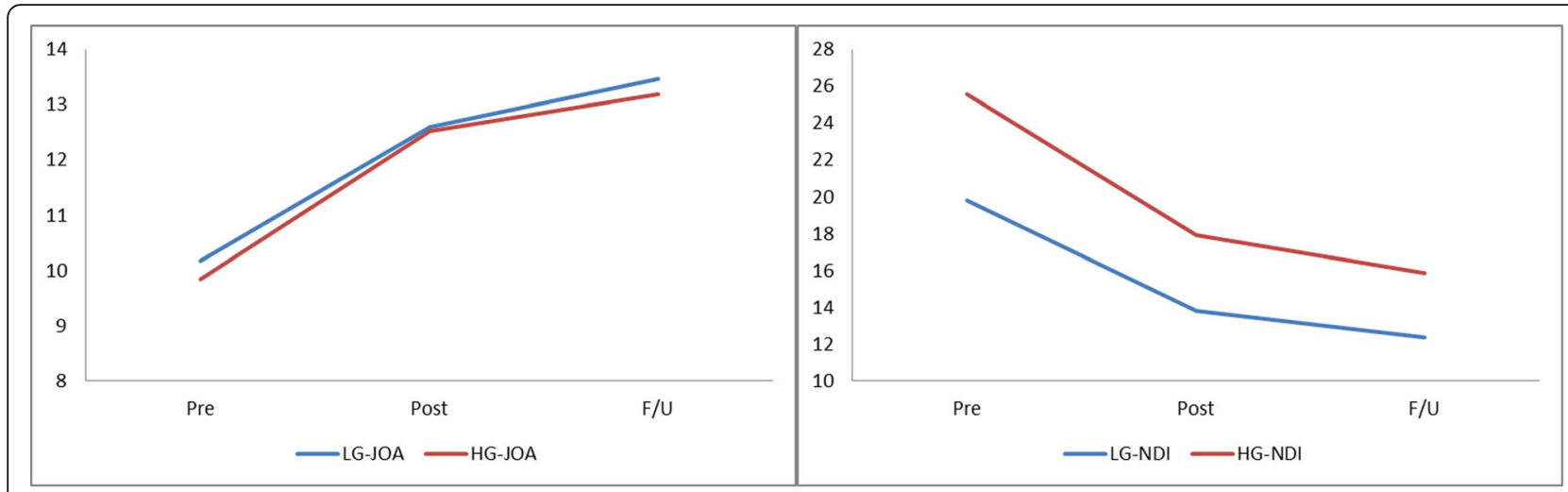

Fig. 4 The change in the clinical results

the correlation of SCA with the NDI for patients with higher SCA increases with follow-up time (post vs F/U: 0.414 vs 0.431 ). Therefore, SCA can be considered another critical parameter for predicting imbalance because excessive SCA may result in significant cervical malalignment. Perhaps this is because the increase of SCA is accompanied by the decrease of $\mathrm{C} 7$ slope and the loss of lordosis after LP $[17,18]$, which would interfere with horizontal vision. Thus, patients may try to compensate cervical balance state by lowering T1s, resulting

Table $\mathbf{5}$ Comparison of cervical radiologic parameters

\begin{tabular}{|c|c|c|c|}
\hline & LG $(n=41)$ & HG $(n=31)$ & $P$ value \\
\hline \multicolumn{4}{|l|}{ SCA $\left(^{\circ}\right)$} \\
\hline Pre & $75.65 \pm 5.08$ & $93.15 \pm 5.25$ & $<0.001$ \\
\hline Post & $81.59 \pm 7.76$ & $95.45 \pm 6.09$ & $<0.001$ \\
\hline F/U & $82.88 \pm 7.42$ & $96.17 \pm 5.26$ & $<0.001$ \\
\hline \multicolumn{4}{|l|}{$\operatorname{T1s}\left({ }^{\circ}\right)$} \\
\hline Pre & $30.23 \pm 5.80$ & $21.42 \pm 4.28$ & $<0.001$ \\
\hline Post & $27.02 \pm 5.52$ & $21.28 \pm 5.82$ & $<0.001$ \\
\hline F/U & $27.41 \pm 4.51$ & $20.73 \pm 4.91$ & $<0.001$ \\
\hline \multicolumn{4}{|l|}{$\mathrm{CA}\left({ }^{\circ}\right)$} \\
\hline Pre & $19.55 \pm 4.97$ & $10.79 \pm 5.45$ & $<0.001$ \\
\hline Post & $17.12 \pm 4.75$ & $9.60 \pm 4.45$ & $<0.001$ \\
\hline F/U & $16.11 \pm 5.07$ & $8.84 \pm 4.50$ & $<0.001$ \\
\hline \multicolumn{4}{|l|}{ cSVA (mm) } \\
\hline Pre & $16.98 \pm 5.52$ & $32.81 \pm 5.24$ & $<0.001$ \\
\hline Post & $22.55 \pm 6.25$ & $35.32 \pm 7.49$ & $<0.001$ \\
\hline F/U 2 years & $24.49 \pm 8.21$ & $36.42 \pm 6.02$ & $<0.001$ \\
\hline \multicolumn{4}{|l|}{$\mathrm{T} 1 \mathrm{sCA}\left({ }^{\circ}\right)$} \\
\hline Pre & $10.68 \pm 3.37$ & $10.63 \pm 7.21$ & 0.348 \\
\hline Post & $9.89 \pm 4.48$ & $11.68 \pm 6.83$ & 0.213 \\
\hline F/U 2 years & $11.30 \pm 4.31$ & $11.89 \pm 6.36$ & 0.661 \\
\hline
\end{tabular}

LG low SCA group, HG high SCA group, SCA spino-cranial angle, T1s T1-Slope, CA C2-7 lordosis angle, CSVA C2-7 sagittal vertical axis, T1sCA T1s minus CA in the stretching of various muscles attached to the neck, which will trigger the threshold of pain and aggrandize energy consumption. Our study showed that, when SCA fluctuates within a certain range less than $85.2^{\circ}$, the cervical vertebra is considered to be within a state of compensation. However, when SCA exceeds the cut-off value, patients might be in a state of cervical decompensation, which results in poorer consequences. It also revealed a prominent positive correlation between SCA and the C2-7 sagittal vertical axis (cSVA) $(r=0.915, P$

Table 6 Comparison of cervical sagittal parameter changes

\begin{tabular}{|c|c|c|c|}
\hline & LG $(n=41)$ & HG $(n=31)$ & $P$ value \\
\hline \multicolumn{4}{|l|}{ SCA $\left(^{\circ}\right)$} \\
\hline$\Delta C A\left(^{\circ}\right)$ (pre vs post) & $5.93 \pm 6.77$ & $2.30 \pm 5.73$ & 0.019 \\
\hline$\Delta \mathrm{CA}\left(^{\circ}\right)$ (pre vs F/U) & $7.23 \pm 6.40$ & $3.02 \pm 5.69$ & 0.005 \\
\hline Pre vs F/U & $<0.001$ & 0.006 & \\
\hline \multicolumn{4}{|l|}{$\operatorname{T1s}\left({ }^{\circ}\right)$} \\
\hline$\Delta \mathrm{T} 1 \mathrm{~s}\left({ }^{\circ}\right)$ (pre vs post) & $-3.21 \pm 4.51$ & $-0.15 \pm 4.80$ & 0.007 \\
\hline$\Delta \mathrm{T} 1 \mathrm{~s}\left({ }^{\circ}\right)($ pre vs F/U) & $-2.81 \pm 3.69$ & $-0.69 \pm 3.99$ & 0.028 \\
\hline Pre vs F/U & $<0.001$ & 0.383 & \\
\hline \multicolumn{4}{|l|}{$\mathrm{CA}\left({ }^{\circ}\right)$} \\
\hline$\Delta \mathrm{CA}\left(^{\circ}\right)$ (pre vs post) & $-2.43 \pm 1.62$ & $-1.19 \pm 2.46$ & 0.005 \\
\hline$\Delta \mathrm{CA}\left({ }^{\circ}\right)($ pre vs F/U) & $-3.43 \pm 2.58$ & $-1.95 \pm 2.93$ & 0.017 \\
\hline Pre vs F/U & $<0.001$ & $<0.001$ & \\
\hline \multicolumn{4}{|l|}{$\mathrm{cSVA}(\mathrm{mm})$} \\
\hline${ }^{\circ} \mathrm{CSVA}(\mathrm{mm})$ (Pre vs post) & $5.57 \pm 5.84$ & $2.52 \pm 6.89$ & 0.055 \\
\hline${ }^{\triangle} \mathrm{CSVA}(\mathrm{mm})($ Pre vs F/U) & $7.51 \pm 8.03$ & $3.61 \pm 5.76$ & 0.019 \\
\hline Pre vs F/U & $<0.001$ & 0.002 & \\
\hline \multicolumn{4}{|l|}{$\mathrm{T} 1 \mathrm{sCA}\left({ }^{\circ}\right)$} \\
\hline$\Delta \mathrm{T} 1 \mathrm{sCA}\left({ }^{\circ}\right)$ (pre vs post) & $-0.79 \pm 4.73$ & $1.05 \pm 4.99$ & 0.126 \\
\hline$\Delta \mathrm{T} 1 \mathrm{~s} C \mathrm{~A}\left({ }^{\circ}\right)($ pre vs F/U) & $0.62 \pm 4.44$ & $1.25 \pm 4.82$ & 0.453 \\
\hline Pre vs F/U & 0.325 & 0.131 & \\
\hline
\end{tabular}

LG low SCA group, HG high SCA group, SCA spino-cranial angle, T1s T1-slope, CA C2-7 lordosis angle, CSVA C2-7 sagittal vertical axis, T1sCA T1s minus CA 


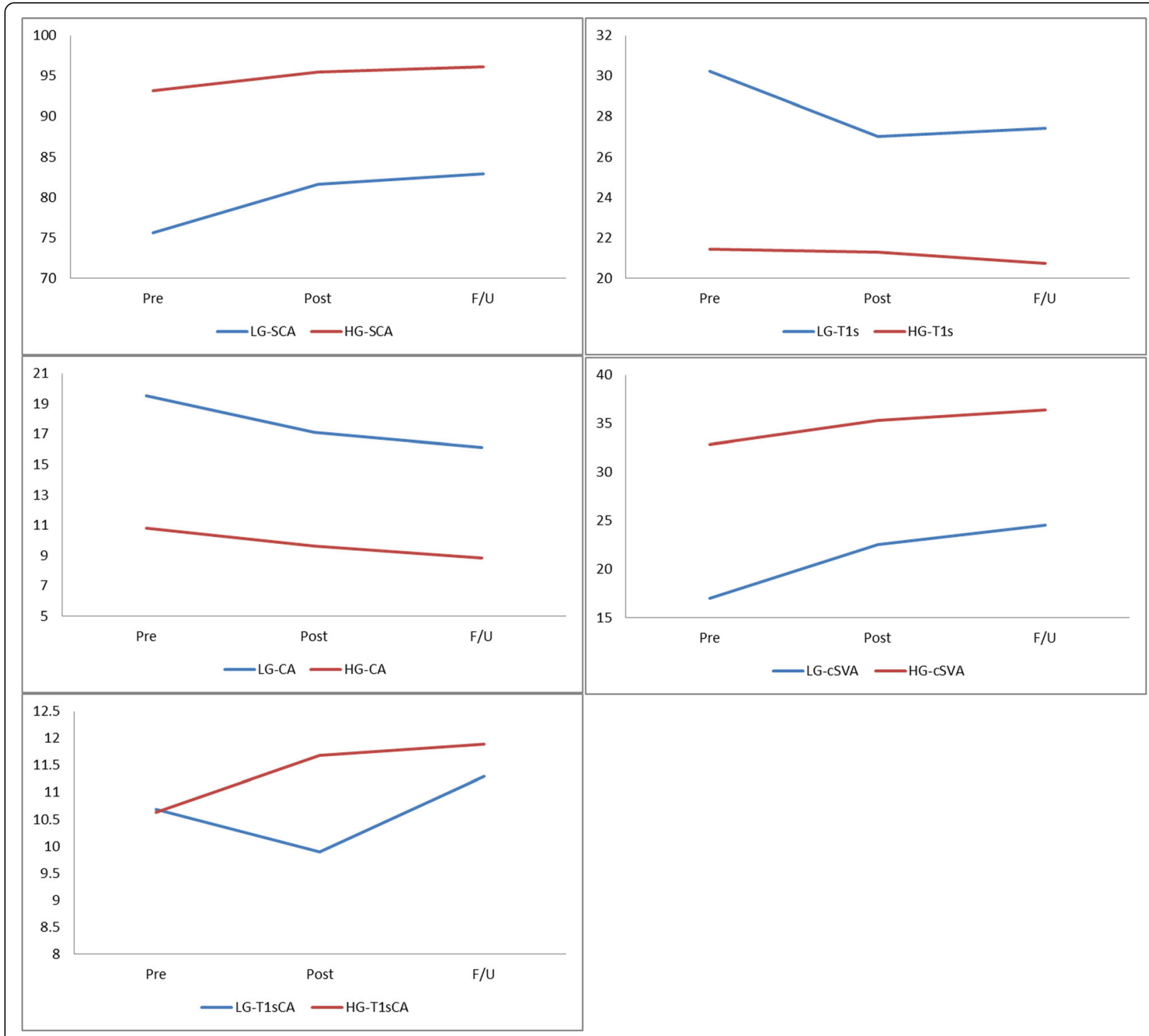

Fig. 5 The change in the radiographic parameters

$<0.001$ ), and cSVA is known to be essential parameter for evaluating health-related outcomes [6, 19-23]. Excessive cSVA was more inclined to express a decrease in cervical lordosis [24-26] and a poorer recovery effect for multilevel cervical spondylotic myelopathy $[18,27]$. The cSVA values of the high SCA group at all observed time points were significantly greater than those of the low SCA group $(P<0.001)$; thus, we considered that SCA increases with increased cSVA. An immoderate SCA may indicate mismatching of the CSVA, which may result in an imbalanced sagittal position of the spine and lead to poorer clinical outcomes. T1sCA $(\mathrm{T} 1 \mathrm{sCA}=\mathrm{T} 1 \mathrm{~s}-\mathrm{CA})$ is used to compensate for the changes of spinal alignment to maintain horizontal gaze $\left(\mathrm{T} 1 \mathrm{sCA} \leq 20^{\circ}\right.$, balance; $>20^{\circ}$, imbalance) [28]. The value of $\mathrm{T} 1 \mathrm{sCA}$ served as a sagittal balance criterion to classify SCA in this study. However, our study did not show a correlation between SCA and T1sCA $(r=0.072, P=0.546)$. The difference between the two groups failed to reach significance (pre: $P=0.348$; post: $P=0.213$; F/U: $P=0.661)$, but T1sCA was always within a reasonable range $\left(<20^{\circ}\right)$ before surgery, postoperatively, and at follow-up, which revealed that T1sCA could effectively compensate to maintain horizontal vision regardless of the SCA value. Meanwhile, patients in the low SCA group had a larger change in all cervical alignment parameters at the follow-up period, and patients in the higher SCA group lacked significant changes in radiographic and clinical indicators after LP surgery, which demonstrated that laminoplasty is an appropriate operating method for patients with a 
lower SCA and mainly ameliorates sagittal balance and relevant clinical outcomes for patients with lower SCA. The most likely reason could be that SCA, T1s, CA, and cSVA were within more suitable ranges in the low SCA group. Thus, we attached importance to the critical parameter SCA, which may be a good predictor of surgery planning. Our research is of great value in understanding the relationship between SCA and clinical outcomes after laminectomy. The value of SCA could be an appropriate indicator for assessing cervical sagittal balance and predicting the changes of cervical alignment after laminectomy.

Our study has certain limitations, such as its retrospective cohort study, shorter follow-up periods, and decreased patient data, which are needed to further confirm the aforementioned results.

\section{Conclusions}

Patients with a lower spino-cranial angle (SCA) were more likely to show a larger sagittal change after laminoplasty and kept better sagittal balance, which led to a preferable surgical outcome. Laminoplasty could be an applicable choice for patients with lower SCA for multilevel cervical spondylotic myelopathy. SCA could be a good predictor of evaluating sagittal balance and planning surgery.

\section{Abbreviations}

MCSM: Multilevel cervical spondylotic myelopathy; SCA: Spino-cranial angle; T1s: T1-slope; CA: C2-C7 lordosis angle; CSVA: C2-C7 sagittal vertical axis; T1sCA: T1s minus CA; LP: Laminoplasty; JOA: Japanese Orthopaedic Association; NDI: Neck Disability Index; ROC: Receiver operating characteristics; HRQOL: Health-related quality of life

\section{Conflict of interest}

The authors declare no conflicts of interest with regard to this manuscript.

\section{Authors' contributions}

DLY conceived and designed the study; ZW and ZL collected; ZW, XWF, and JYS analyzed and interpreted the patient data. ZW and ZWW wrote the paper. All authors read and approved the final manuscript. All authors have read the journal policies and have no issues relating to journal policies. All authors have seen the manuscript and approved to submit to your journal. The work described has not been submitted elsewhere for publication, in whole or in part. The authors read and approved the final manuscript.

\section{Funding}

None.

\section{Availability of data and materials}

The datasets generated and analyzed during the current study are available from the corresponding author on reasonable request.

\section{Ethics approval and consent to participate}

This article does not contain any studies with human participants or animals performed by any of the authors.
Received: 9 October 2020 Accepted: 3 January 2021

Published online: 12 January 2021

\section{References}

1. Chiba K, Ogawa Y, Ishii K, et al. Long-term results of expansive open-door laminoplasty for cervical myelopathy--average 14-year follow-up study. Spine. 2006;31(26):2998-3005.

2. Kawaguchi $Y$, Nakano $M$, Yasuda $T$, et al. More than 20 years follow-up after en bloc cervical laminoplasty. Spine. 2016:41(20):1570-9.

3. Aita I, Wadano Y, Yabuki T. Curvature and range of motion of the cervical spine after laminaplasty. J Bone Joint Surg Am Vol. 2000;82(12):1743-8.

4. Ling FP, Chevillotte $T$, Leglise A, et al. Which parameters are relevant in sagittal balance analysis of the cervical spine? A literature review. Eur Spine J. 2018;27(Suppl 1):8-15

5. Le Huec JC, Demezon H, Aunoble S. Sagittal parameters of global cervical balance using EOS imaging: normative values from a prospective cohort of asymptomatic volunteers. Eur Spine J. 2015;24(1):63-71.

6. Tang JA, Scheer JK, Smith JS, et al: The impact of standing regional cervical sagittal alignment on outcomes in posterior cervical fusion surgery. Neurosurgery 2015, 76 Suppl 1:S14-S21; discussion S21.

7. Youn MS, Shin JK, Goh TS, et al. Relationship between cervical sagittal alignment and health-related quality of life in adolescent idiopathic scoliosis. Eur Spine J. 2016;25(10):3114-9.

8. Edwards CC 2nd, Riew KD, et al. Cervical myelopathy: current diagnostic and treatment strategies. Spine J. 2003;3(1):68-81.

9. Hida $T$, Sakai $Y$, Ito $K$, et al. Collar fixation is not mandatory after cervical laminoplasty: a randomized controlled trial. Spine. 2017;42(5):E253-9.

10. Luo W, Li Y, Zhao J, et al. Open-versus French-door laminoplasty for the treatment of cervical multilevel compressive myelopathy: a meta-analysis. World Neurosurg. 2018;117:129-36.

11. Luo W, Li Y, Zhao J, et al. Skip laminectomy compared with laminoplasty for cervical compressive myelopathy: a systematic review and meta-analysis. World Neurosurg. 2018;120:296-301.

12. Sodeyama T, Goto S, Mochizuki M, et al: Effect of decompression enlargement laminoplasty for posterior shifting of the spinal cord. Spine 1999, 24(15):1527-1531; discussion 1531-1522.

13. Lin S, Zhou F, Sun Y, et al. The severity of operative invasion to the posterior muscular-ligament complex influences cervical sagittal balance after open-door laminoplasty. Eur Spine J. 2015;24(1):127-35.

14. Sakai K, Yoshii T, Hirai T, et al. Impact of the surgical treatment for degenerative cervical myelopathy on the preoperative cervical sagittal balance: a review of prospective comparative cohort between anterior decompression with fusion and laminoplasty. Eur Spine J. 2017;26(1):104-12.

15. Suda K, Abumi K, Ito M, et al. Local kyphosis reduces surgical outcomes of expansive open-door laminoplasty for cervical spondylotic myelopathy. Spine. 2003:28(12):1258-62.

16. Iyer S, Nemani VM, Nguyen J, et al. Impact of cervical sagittal alignment parameters on neck disability. Spine. 2016:41(5):371-7.

17. Cabraja M, Abbushi A, Koeppen D, et al. Comparison between anterior and posterior decompression with instrumentation for cervical spondylotic myelopathy: sagittal alignment and clinical outcome. Neurosurg Focus. 2010;28(3):E15

18. Tang JA, Scheer JK, Smith JS, et al: The impact of standing regional cervical sagittal alignment on outcomes in posterior cervical fusion surgery. Neurosurgery 2012, 71(3):662-669; discussion 669.

19. Huang $Y$, Lan Z, Xu W. Analysis of sagittal alignment parameters following anterior cervical hybrid decompression and fusion of multilevel cervical spondylotic myelopathy. BMC Musculoskelet Disord. 2019;20(1):1.

20. Kwon WK, Kim PS, Ahn SY, et al. Analysis of associating factors with C2-7 sagittal vertical axis after two-level anterior cervical fusion: comparison between plate augmentation and stand-alone cages. Spine. 2017:42(5):318-25.

21. Lee HD, Jeon $\mathrm{CH}$, Chung NS, et al. Comparative analysis of three imaging modalities for evaluation of cervical sagittal alignment parameters: a validity and reliability study. Spine. 2017;42(24):1901-7.

22. Lee SH, Kim KT, Seo EM, et al. The influence of thoracic inlet alignment on the craniocervical sagittal balance in asymptomatic adults. J Spinal Disord Tech. 2012;25(2):E41-7.

23. Villavicencio AT, Babuska JM, Ashton A, et al: Prospective, randomized, double-blind clinical study evaluating the correlation of clinical outcomes and cervical sagittal alignment. Neurosurgery 2011, 68(5):1309-1316; discussion 1316. 
24. Kim TH, Lee SY, Kim YC, et al. T1 slope as a predictor of kyphotic alignment change after laminoplasty in patients with cervical myelopathy. Spine. 2013; 38(16):E992-7.

25. Sakai K, Yoshii T, Hirai T, et al. Cervical sagittal imbalance is a predictor of kyphotic deformity after laminoplasty in cervical spondylotic myelopathy patients without preoperative kyphotic alignment. Spine. 2016;41(4):299-305.

26. Zhang JT, Li JQ, Niu RJ, et al. Predictors of cervical lordosis loss after laminoplasty in patients with cervical spondylotic myelopathy. Eur Spine J. 2017;26(4):1205-10.

27. Smith JS, Lafage V, Ryan DJ, et al. Association of myelopathy scores with cervical sagittal balance and normalized spinal cord volume: analysis of 56 preoperative cases from the AOSpine North America Myelopathy study. Spine. 2013:38(22 Suppl 1):S161-70

28. Ames CP, Smith JS, Eastlack R, et al. Reliability assessment of a novel cervical spine deformity classification system. J Neurosurg Spine. 2015;23(6):673-83.

\section{Publisher's Note}

Springer Nature remains neutral with regard to jurisdictional claims in published maps and institutional affiliations.

Ready to submit your research? Choose BMC and benefit from:

- fast, convenient online submission

- thorough peer review by experienced researchers in your field

- rapid publication on acceptance

- support for research data, including large and complex data types

- gold Open Access which fosters wider collaboration and increased citations

- maximum visibility for your research: over $100 \mathrm{M}$ website views per year

At BMC, research is always in progress.

Learn more biomedcentral.com/submissions 